\title{
Harmonização orofacial: análise do conhecimento dos Cirurgiões-Dentistas sobre os riscos clínicos e aspectos legais e éticos na prática da rinomodelação e bichectomia
}

Orofacial harmonization: analysis of Dentists" knowledge about clinical risks and legal and ethical aspects in the practice of rhinomodeling and bichectomy

Armonización orofacial: análisis del conocimiento de los Odontólogos sobre riesgos clínicos y aspectos legales y éticos em la práctica de la rinomodelado y bichectomía

Recebido: 21/01/2021 | Revisado: 23/01/2021 | Aceito: 25/01/2021 | Publicado: 01/02/2021

Lívia Graziele Rodrigues

ORCID: https://orcid.org/0000-0002-6218-4015 Universidade Federal de Goiás, Brasil E-mail: liviagrodriguez@gmail.com

João Batista de Souza

ORCID: https://orcid.org/0000-0003-0327-4077 Universidade Federal de Goiás, Brasil E-mail: jbs.ufg@gmail.com

Douglas Rangel Goulart

ORCID: https://orcid.org/0000-0001-8339-3660 Universidade Federal de Goiás, Brasil

E-mail: douglasgoulart@ufg.br

Ademir Franco

ORCID: https://orcid.org/0000-0002-1417-2781 Faculdade São Leopoldo Mandic, Brasil E-mail: Ademir.junior@slmandic.edu.br Paulo Eduardo Miamoto Dias ORCID: https://orcid.org/0000-0003-0247-9433 Instituto Geral de Perícias de Santa Catarina, Brasil E-mail:dr.miamoto@gmail.com

Rhonan Ferreira Silva

ORCID: https://orcid.org/0000-0002-3680-7020 Universidade Federal de Goiás, Brasil E-mail: rhonansilva@gmail.com

\begin{abstract}
Resumo
A harmonização orofacial consiste em tornar os terços da face de um paciente mais aceitáveis esteticamente por meio de procedimentos como: preenchimento facial com biomateriais, aplicação da toxina botulínica, bichectomia, lipoaspiração cervical e rinomodelação. O objetivo desse estudo é avaliar a percepção dos Cirurgiões-dentistas a respeito da capacidade técnica para executar procedimentos de rinomodelação e bichectomia quanto ao respaldo legal para sua execução. Após aprovada em comitê de ética a presente pesquisa, foi aplicado, aos profissionais que se dispuseram a participar, um questionário estruturado autoaplicável com 15 questões que versam sobre o perfil do participante, tópicos de harmonização orofacial e os assuntos específicos sobre bichectomia e rinomodelação. Dos 180 questionários respondidos, $105(58,3 \%)$ eram de profissionais do gênero feminino, 41 (22,9\%) afirmaram realizar procedimentos de harmonização orofacial em sua rotina clínica. Questionados ainda sobre estarem aptos a tratar uma necrose nasal já instalada, $19(11,0 \%)$ participantes declararam estar aptos a proceder com esse tipo de tratamento, enquanto 110 (72,8\%) deles informaram que encaminhariam esse caso para um Médico. Foi possível perceber que, de forma geral, os profissionais não tem conhecimento das normativas que os respaldam quanto à execução de novos procedimentos incluídos ao rol dos que a Odontologia já pratica, além disso, mesmo os profissionais que frequentaram cursos de capacitação em Harmonização Orofacial, grande parte não se sente confiante para realizar procedimentos como rinomodelação e tratar suas complicações.
\end{abstract}

Palavras-chave: Odontologia legal; Preenchedores dérmicos; Ácido hialurônico; Cirurgia bucal.

\footnotetext{
Abstract

Orofacial harmonization consists of making the patient's face more aesthetically acceptable through procedures such as: facial filling with biomaterials, application of botulinum toxin, bichectomy, cervical liposuction and rhinomodeling. The objective of this study is to evaluate the perception of dentists regarding the skills for rhinomodeling and bichectomy procedures regarding the legal support for their performance. After the ethics
} 
committee approved this research, a self-administered structured questionnaire with 15 questions about the participant's profile, topics on orofacial harmonization and specific subjects about bichectomy and rhinomodulation, was prepared for the professionals who were willing to participate. Of the 180 questionnaires answered, 105 (58.3\%) were from female professionals, $41(22.9 \%)$ said they performed orofacial harmonization procedures in their clinical routine. When asked about being able to treat an already installed nasal necrosis, $19(11.0 \%)$ participants declared that they were able to proceed with this type of treatment, while $110(72.8 \%)$ informed that they would refer this case to a Doctor. It was possible to observed that, in general, professionals are not aware of the norms that support the execution of new procedures included among those traditionally practiced in Dentistry. In addition, from the professionals who attended training courses in Orofacial Harmonization, most of them do not feel confident to perform procedures such as rhinomodeling.

Keywords: Forensic dentistry; Dermal fillers; Hyaluronic acid; Surgery oral.

\section{Resumen}

La armonización orofacial consiste en hacer más aceptables estéticamente los tercios del rostro del paciente mediante procedimientos como: relleno facial con biomateriales, aplicación de toxina botulínica, bichectomía, liposucción cervical y rinomodelación. El objetivo de este estudio es evaluar la percepción de los odontólogos sobre la capacidad técnica de los procedimientos de rinomodelación y bichectomía en cuanto al sustento legal para su ejecución. Luego de la aprobación de la investigación por parte del comité de ética, se elaboró un cuestionario estructurado autoadministrado con 15 preguntas sobre el perfil del participante, tópicos de armonización orofacial y disciplinas específicas en bichectomía y rinomodelación, para profesionales que estuvieran dispuestos a participar. De los 180 cuestionarios respondidos, $105(58,3 \%)$ eran de mujeres profesionales, 41 (22,9\%) dijeron que realizaban procedimientos de armonización orofacial en su rutina clínica. Cuando se les preguntó cómo tratar una necrosis nasal ya instalada, $19(11,0 \%)$ participantes declararon que podían continuar con este tipo de tratamiento, mientras que 110 $(72,8 \%)$ informaron que derivarían el caso al médico. Se pudo percibir que, en general, los profesionales desconocen las normas que los sustentan en cuanto a la implementación de nuevos procedimientos incluidos en la lista de Odontología ya practicada. Incluso, de los profesionales que tomaron cursos de formación en Armonización Orofacial, la mayoría de ellos declaran no sentirse seguros para realizar procedimientos como el rinomodelación y tratar sus complicaciones.

Palabras clave: Odontología forense; Rellenos dérmicos; Ácido hialurónico; Cirurgía bucal.

\section{Introdução}

A utilização de substâncias com finalidade estética vem sendo aprimorada ao longo dos anos. O bloqueio neuromuscular com a toxina botulínica começou a ser estudado por volta de 1949 (Erbguth, 2008), e décadas mais tarde ela começou a ser utilizada para tratamento de patologias como estrabismo, blefaroespasmo e distonia muscular (França, et al., 2017). Por volta dos anos 2000 essa toxina foi aprovada pela FDA para uso cosmético com o intuito de inativação de rugas em regiões glabelar, de testa e lateral do músculo orbicular do olho, além de regiões como pescoço e músculos mastigatórios que estejam hiperreativos (Niamtu, 1999; França, et al., 2017; Santamato \& Panza, 2017). Substâncias que têm a finalidade de preencher tecidos faciais também foram sendo desenvolvidas e investigadas. O propósito inicial desses materiais, que era adicionar volume nas regiões em que fosse aplicado, com o avanço de pesquisas a intenção passou a ser também, a estimulação de produção de colágeno, sendo cada vez mais aceitos produtos à base de ácido hialurônico por possuírem maior compatibilidade biológica com os tecidos (Papazian, et al., 2018; Lima \& Soares, 2020).

Até o início do século XXI, os tratamentos como movimentação ortodôntica associados ao reposicionamento maxilomandibular por meio de cirurgia ortognática eram descritos como sendo procedimentos de harmonização da face, e remetiam, claramente, ao vínculo de resultado funcional e/ou estético (Brasil, Res. CFO - 063, 2005). Nesse exemplo, os recursos terapêuticos visam proporcionar ao paciente a conquista da melhora na qualidade de vida, ganho estético e das funções fonética, mastigatória e respiratória, o que fez com que alguns tratamentos odontológicos se encaixassem no conceito de harmonização facial (Ribas, et al., 2005).

O constante aprimoramento de técnicas e materiais para o uso estético em saúde fez com que a Harmonização Orofacial (HOF) também recebesse uma nova caracterização, fazendo com que a essência da busca pela beleza e simetria da 
face fosse também estendida ao campo de atuação de diversas profissões não médicas incluindo a Odontologia. Atualmente, a HOF empenha-se em tornar os terços da face de um paciente visualmente mais proporcionais e próximos do supostamente natural por meio de procedimentos invasivos (em maior ou menor intensidade) como: preenchimento com biomateriais, aplicação da toxina botulínica em áreas estéticas para diminuição de linhas de expressão e rugas na pele, lifting nasolabial - lip lifting, bichectomia - lipoplastia facial, lipoplastia cervical também conhecida como lipo de papada e a rinomodelação rinoplastia (Vargas, et al., 2009; Cardim, et al., 2011; Trindade de Almeida \& Araújo Sampaio, 2015; Coimbra, et al., 2015; Parada, et al., 2016; Alvarez \& Siqueira, 2018). Entretanto, ao permear o campo da estética facial, muitos cirurgiões-dentistas vêm executando diversos procedimentos invasivos, e considerados controversos no campo de atuação desses profissionais uma vez que poderiam ser atos privativos da medicina (Jacometti, et al., 2017).

No Brasil, as discussões normativas com o intuito de regulamentar as práticas de HOF por cirurgiões-dentistas foi iniciada em 2011 (Brasil, Res. CFO - 112, 2011), mas somente em 2016 houve a aprovação da Resolução CFO - 176 que autorizou o uso do ácido hialurônico e toxina botulínica para fins estéticos em Odontologia (Brasil, Res. CFO - 176, 2016). A partir de então, os procedimentos de preenchimento facial e aplicação da toxina botulínica com finalidade estética têm sido habitualmente oferecidos em consultórios odontológicos com o intuito de corrigir alterações que podem ocorrer ao longo dos anos no contorno e volume da face e lábios e, no caso da toxina botulínica, prevenir a intensificação dos sulcos já existentes na pele e a formação de novos sinais de expressão (Magri \& Maio, 2016). Além de serem corriqueiramente ofertados no mercado de consumo em saúde, a procura por esses tipos de tratamentos tem aumentado a cada dia em virtude de apresentarem resultados imediatos, satisfatórios e mais próximos do natural, sem que haja a necessidade de recorrer a um procedimento mais invasivo, como a cirurgia plástica (Maia \& Salvi, 2018). Como último ato normativo, em 2019, a Harmonização Orofacial foi reconhecida como especialidade odontológica por meio da Resolução CFO - 198 (Brasil, Res. CFO - 198, 2019).

Com respaldo normativo, os profissionais da Odontologia estão cada vez mais procurando aprimoramento técnico e o número de procedimentos está aumentando significativamente, o que também reflete o número de intercorrências e insucessos. Conhecer as indicações e contraindicações dos materiais e produtos bem como das técnicas a serem empregadas em HOF é de suma importância para se obter o sucesso nos tratamentos (Santamato \& Panza, 2017).

Dentre os vários materiais preenchedores disponíveis no mercado, o ácido hialurônico (AH) - Rennova ${ }^{\circledR}$, Princess ${ }^{\circledR}$, Hialurox ${ }^{\circledR}$ - tem sido muito difundido, principalmente na Odontologia, nos últimos anos. Por ser uma substância que está presente no corpo humano, em maior quantidade na pele, o ácido hialurônico pode ser administrado para preenchimento de sulcos, rugas e aumento de volume, além de promover uma melhora na hidratação, tônus e elasticidade da pele. Esse preenchedor possui ainda baixo risco de alergias, não induz reações inflamatórias, não possui substâncias carcinogênicas e é altamente compatível biologicamente (Crocco, et al., 2012; Trindade de Almeida \& Araújo Sampaio, 2015; Magri \& Maio, 2016; Silva Neto, et al., 2019).

Alguns preenchedores faciais também são empregados na rinomodelação. Essa técnica consiste em corrigir/alterar, de maneira não cirúrgica, o formato e posicionamento do dorso e do ápice do nariz por meio da infiltração de biomateriais em áreas específicas as quais se deseja corrigir, fazendo com que o nariz que apresente um aspecto adunco possa exibir um dorso mais reto com o ápice nasal mais elevado (Vargas, et al., 2009; Talarico, et al., 2010; Chen, et al., 2016). Dessa forma, a técnica de rinomodelação tem se popularizado entre pacientes que se sentem incomodados com o aspecto morfológico de seu nariz, mas que não estão dispostos a se submeterem a um procedimento cirúrgico para que a estética esperada seja estabelecida. Apesar de essa técnica ser considerada simples e poder ser empregada em diversos casos, ela também possui limitações não sendo possível corrigir qualquer caso, além de estar sujeita a complicações que possam gerar maiores prejuízos estéticos como a necrose nasal (Fadanelli, et al., 2007; Coimbra, et al., 2015; Manafi, et al., 2015; Nassif, 2015; Chen, et al., 2016; Sahan, et al., 2017). 
A bichectomia ou bichatectomia, conhecida ainda como lipoplastia facial, consiste na remoção cirúrgica de parte do corpo adiposo da bochecha, também conhecido como "bola de Bichat" - de onde deriva o nome "bichectomia" (Alvarez \& Siqueira, 2018). Essa estrutura anatômica localiza-se, em sua maior porção, entre os músculos bucinador e masseter e se estende superiormente em formato cônico até a fossa infratemporal (Madeira, 2012). Essa cirurgia é realizada com o intuito de reduzir o volume das bochechas, tanto para diminuir a incidência de mordiscato nas mucosas jugais quanto com finalidade unicamente estética, ou seja, é capaz de acentuar a projeção do osso zigomático produzindo o efeito de rosto mais afilado (Zhang, et al., 2002; Xu \& Yu, 2013; Benjamin \& Reish, 2018; Faria, et al., 2018).

Todo e qualquer procedimento estético do menos invasivo, como a utilização de cremes faciais, até ao mais invasivo deles, como uma cirurgia plástica por exemplo oferece riscos e pode apresentar complicações aos pacientes que se submetem a esses tratamentos. Nesses casos, as complicações geralmente podem estar associadas a fatores como processos alérgicos, variações anatômicas, má indicação de produtos e erro de técnica (Vargas, et al., 2009; Crocco, et al., 2012; Tamura, 2013; Parada, et al., 2016).

Com relação aos preenchedores, existem áreas de infiltração desses produtos que são classificadas como sendo de maior risco de produzir complicações, o que não significa que elas também não possam ocorrer nas demais regiões da face (Tamura, 2013). Apesar de ser um produto extremamente biocompatível, a aplicação do ácido hialurônico também pode promover efeitos adversos como edema, dor, eritema, coceira e equimose (Hong, et al., 2019). A oclusão de vasos distais pode promover o escurecimento cutâneo, formação de ulcerações e escaras (Trindade de Almeida \& Araújo Sampaio, 2015). A embolização iatrogênica da artéria oftálmica, pela administração de ácido hialurônico, ocasionando cegueira é uma complicação rara, e o reconhecimento precoce e tratamento desse tipo de complicação pode ser crucial para o desfecho do caso (Chatrath, et al., 2019; Shoughy, 2019). Além disso, a oclusão acidental de artérias acontece mais em consequência dos tratamentos realizados no nariz, podendo ser ocasionada ainda por procedimentos realizados na glabela (Kim, et al., 2015; Sito, et al., 2019).

A bichectomia é um dos procedimentos de HOF mais procurados. Como qualquer procedimento cirúrgico, edema e equimoses podem ser percebidas com maior frequência no pós-operatório. A infecção pode estar presente em alguns casos, sendo a parestesia facial - decorrente de lesão no nervo facial que se localiza próximo ao corpo adiposo da bochecha - e lesão traumática do ducto parotídeo - devido a incisão cirúrgica em local inadequado ou decorrente de variação anatômica do indivíduo - são as complicações, mais severas e de difícil tratamento, que podem acometer pacientes que se submetem a esse tipo de tratamento cirúrgico (Klüppel, et al., 2018). É importante que esse tipo de cirurgia não seja trivializada e que possa ser indicada de forma correta, sendo fundamental o conhecimento cirúrgico e anatômico para evitar as complicações que possam ocorrer (Ahari, et al., 2016; Alvarez \& Siqueira, 2018).

Apesar de estar regulamentada normativamente a prática da HOF na Odontologia, é tênue o limite entre os procedimentos autorizados para o cirurgião-dentista na HOF e os procedimentos estéticos e privativos da medicina, o que suscitou a publicação da Res. CFO - 230/2020, que regulamentou o artigo $3^{\text {o }}$ da Res. CFO - 198/2019, com o objetivo de esclarecer o termo "áreas afins” utilizado na Res. CFO - 198/2019 (Brasil, Res. CFO - 230, 2020). Ultrapassar esse limite pode gerar embates judiciais e éticos, colocando em risco não só a imagem da profissão como também a saúde dos pacientes.

Tendo em vista que a literatura na área de saúde relacionada à prática da HOF por dentistas é escassa, o objetivo do presente estudo é avaliar o conhecimento dos Cirurgiões-dentistas a respeito da prática da harmonização orofacial, enfatizando a análise dos riscos inerentes aos procedimentos de bichectomia e rinomodelação, e discutindo as repercussões legais e éticas quando diante de intercorrências ou do insucesso terapêutico. 


\section{Metodologia}

O presente estudo, que é do tipo transversal descritivo, foi desenvolvido após ter sido aprovado no Comitê de Ética em Pesquisa da Universidade Federal de Goiás sob número da CAAE 06066319.1.0000.5083.

\section{Da realização da pesquisa}

Foram convidados a partipar dessa pesquisa profissionais que estiveram presentes nos congressos organizados pela Associação Brasileira de Odontologia - Goiás, Associação Brasileira de Ortodontia - Goiás e Equipe de Cirurgia e Traumatologia Bucomaxilofacial do HUGOL durante o ano de 2018. Após manifestarem interesse em participar da pesquisa, era disponibilizado o Termo de Consentimento Livre e Esclarecido (TCLE) referente à pesquisa e o questionário estruturado para coleta de dados. Foi possível distribuir a aproximadamente 300 congressistas.

\section{Estrutura do questionário}

Para o questionário foram elaboradas 16 perguntas estruturadas que versavam sobre o perfil do participante e seus conhecimentos clínicos, éticos e legais sobre HOF, e, especificamente sobre os procedimentos de bichectomia e rinomodelação. Foi realizado um estudo piloto com o intuito de avaliar a precisão desse instrumento na coleta de dados. Algumas questões foram readequadas para melhor compreensão dos participantes da pesquisa, sendo excluídas da amostra as respostas referentes ao estudo piloto.

Esse instrumento foi aplicado presencialmente e continha em seu cabeçalho breves instruções de como deveriam ser respondidas as questões, estimando-se o tempo máximo de quinze minutos para o seu completo preenchimento. Além disso, os membros da equipe de pesquisa sempre estavam disponíveis próximos aos participantes para auxiliá-los no preenchimento das perguntas quando necessário (Pereira, et al., 2018).

\section{Análise estatística}

Os dados obtidos, por meio do questionário, foram tabulados em uma planilha elaborada no software EXCEL 2010 e posteriormente exportadas para o programa IBM SPSS Statistics - versão 21 (Statistical Product And Service Solutions) para realização da análise estatística.

Além da análise descritiva (porcentagem simples), utilizou-se o teste Qui-Quadrado de Pearson $\left(\mathrm{X}^{2}\right)$ com um nível de significância de $5 \%(\mathrm{p}<0,05)$ para avaliar a associação entre as seguintes variáveis (Tabela 1): 
Tabela 1. Associação das variáveis para análise estatística.

\section{Questões associadas}

\begin{tabular}{|c|c|}
\hline \multirow{4}{*}{$\begin{array}{c}\text { Questão 2. Há } \\
\text { quanto tempo } \\
\text { concluiu a } \\
\text { Graduação }\end{array}$} & Questão 5. Quais procedimentos executa \\
\hline & Questão 11. Quais procedimentos o dentista possui respaldo ético/ normativo para executar \\
\hline & Questão 12. Quais intercorrências podem surgir em decorrência da rinomodelação \\
\hline & Questão 13. Considera-se apto a tratar caso de necrose nasal instalada \\
\hline \multirow{3}{*}{$\begin{array}{c}\text { Questão 3. } \\
\text { Quais } \\
\text { especialidades } \\
\text { possui }\end{array}$} & Questão 14. Para quem encaminharia o paciente com necrose nasal instalada \\
\hline & Questão 15. Quais intercorrências podem surgir em decorrência da bichectomia \\
\hline & Questão 16. Quais intercorrências consegue tratar durante/após a cirurgia de bichectomia \\
\hline \multirow{8}{*}{$\begin{array}{c}\text { Questão 4. } \\
\text { Realiza } \\
\text { procedimentos } \\
\text { de } \\
\text { Harmonização } \\
\text { Orofacial (HOF) } \\
\text { na rotina clínica }\end{array}$} & Questão 2. Há quanto tempo concluiu a Graduação \\
\hline & Questão 5. Quais procedimentos executa \\
\hline & Questão 11. Quais procedimentos o dentista possui respaldo ético/ normativo para executar \\
\hline & Questão 12. Quais intercorrências podem surgir em decorrência da rinomodelação \\
\hline & Questão 13. Considera-se apto a tratar caso de necrose nasal instalada \\
\hline & Questão 14. Para quem encaminharia o paciente com necrose nasal instalada \\
\hline & Questão 15. Quais intercorrências podem surgir em decorrência da bichectomia \\
\hline & Questão 16. Quais intercorrências consegue tratar durante/após a cirurgia de bichectomia \\
\hline $\begin{array}{l}\text { Profissionais } \\
\text { que realizam } \\
\text { bichectomia em } \\
\text { sua rotina } \\
\text { clínica }\end{array}$ & Questão 16. Quais intercorrências consegue tratar durante/após a cirurgia de bichectomia \\
\hline
\end{tabular}

Fonte: Autores (2021).

\section{Resultados}

Dos 300 questionários distribuídos, foram devolvidos para análise 180 (60,0\%) deles. Por se tratar de um questionário com perguntas de múltipla escolha e de resposta única, aliado ao fato de que o participante poderia deixar de responder alguma questão por não se sentir confortável, o espaço amostral obtido variou entre 133 a 180, sendo as questões 7 e 16 as com maior número de abstenções (Tabela 2). 
Tabela 2. Espaço amostral de acordo com a questão analisada. ( $\mathrm{N}=180)$.

\begin{tabular}{|c|c|c|}
\hline Questões & $\begin{array}{c}\text { Respostas } \\
\text { Válidas }\end{array}$ & $\begin{array}{c}\text { Respostas } \\
\text { Ausentes }\end{array}$ \\
\hline Q 1. Sexo & 180 & 0 \\
\hline Q 2. Há quanto tempo concluiu a Graduação & 180 & 0 \\
\hline Q 3. Quais especialidades possui & 168 & 12 \\
\hline Q 4. Realiza procedimentos de Harmonização Orofacial (HOF) na rotina clínica & 179 & 1 \\
\hline Q 5. Quais procedimentos executa & 170 & 10 \\
\hline Q 6. Frequentou curso de Harmonização Orofacial (HOF) & 175 & 5 \\
\hline Q 7. Qual duração do curso & 133 & 47 \\
\hline Dos que frequentaram o curso de HOF & 57 & 1 \\
\hline Q 8. Quais procedimentos foram abordados no curso & 166 & 14 \\
\hline Dos que frequentaram o curso de HOF & 57 & 1 \\
\hline Q 9. Houve abordagem ético-legal no curso & 160 & 20 \\
\hline Dos que frequentaram o curso de HOF & 53 & 5 \\
\hline Q 10. Quais procedimentos foram abordados no curso & 167 & 13 \\
\hline Q 11. Quais procedimentos o dentista possui respaldo ético/ normativo para executar & 170 & 10 \\
\hline Q 12. Quais intercorrências podem surgir em decorrência da rinomodelação & 171 & 9 \\
\hline Q 13. Considera-se apto a tratar caso de necrose nasal instalada & 173 & 7 \\
\hline Q 14. Para quem encaminharia o paciente com necrose nasal instalada & 156 & 24 \\
\hline Q 15. Quais intercorrências podem surgir em decorrência da bichectomia & 171 & 9 \\
\hline Q 16. Quais intercorrências consegue tratar durante/após a cirurgia de bichectomia & 154 & 26 \\
\hline
\end{tabular}

Fonte: Autores (2021).

Participaram dessa pesquisa $75(41,7 \%)$ cirurgiões-dentistas do sexo masculino e $105(58,3 \%)$ do sexo feminino, e com relação ao tempo de formado, maioria dos participantes (80 - 44,4\%) havia se graduado há menos de 6 anos (Figura 1). 
Figura 1. Frequência da profissionais de acordo com seu tempo de formados. $(\mathrm{N}=180)$.

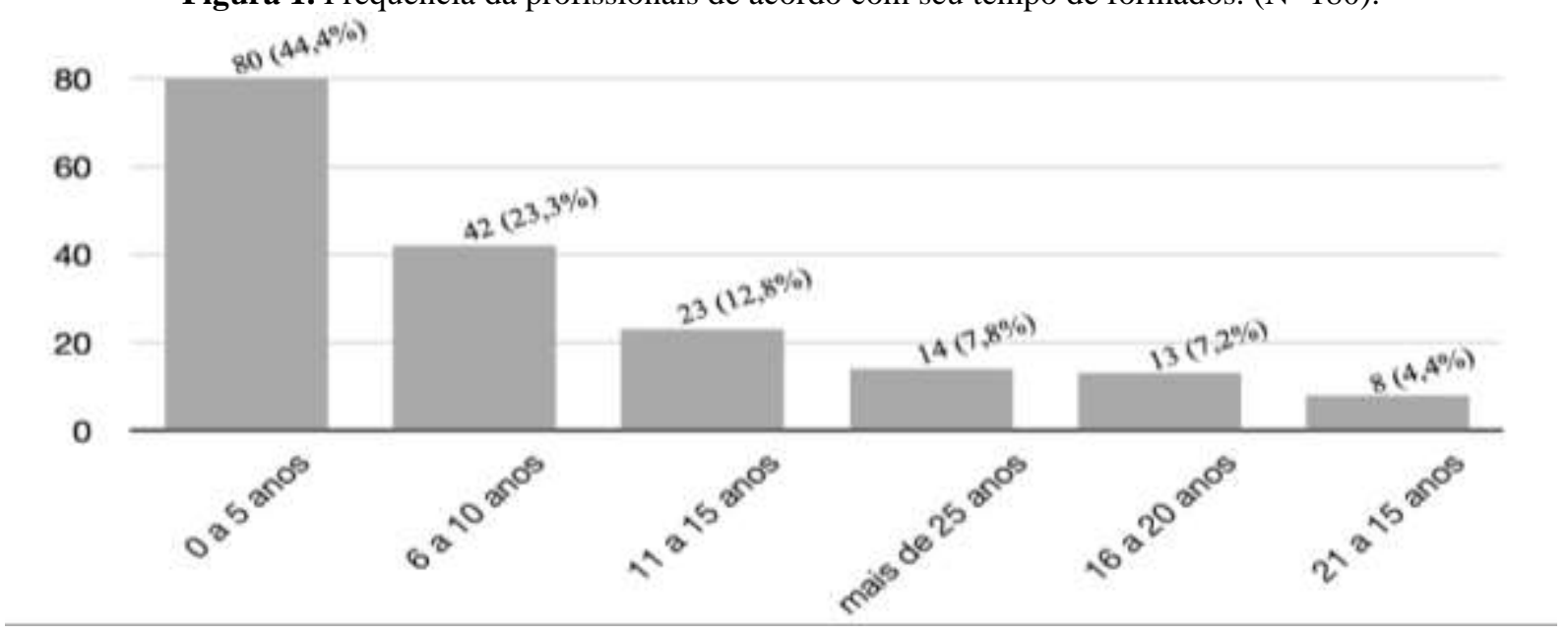

Fonte: Autores (2021).

Com relação às especialidades que esses participantes possuíam, 99 (55,0\%) relataram ter cursado uma, $38(21,1 \%)$ duas especialidades, $3(1,6 \%)$ três especialidades, $1(0,5 \%)$ quatro especialidade e $27(15,0 \%)$ disseram não ter se especializado em nenhuma área da odontologia. As especialidades mais frequentes na pesquisa foram ortodontia e implantodontia (Figura 2).

Figura 2. Frequência da especialidade segundo a amostra. $(\mathrm{N}=168)$.

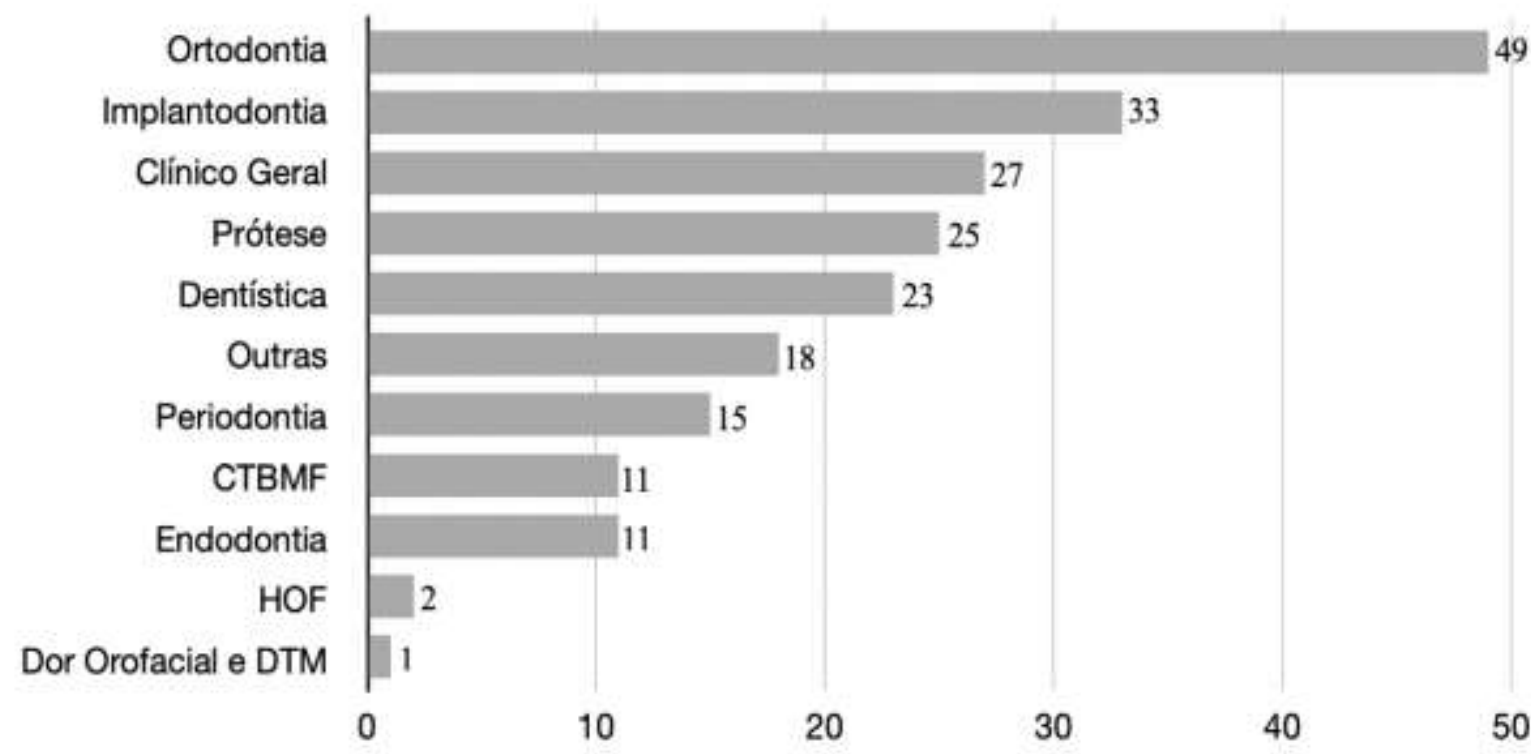

Fonte: Autores (2021).

Com relação à realização de procedimentos de Harmonização Orofacial (HOF), 41 (22,9\%) participantes admitiram que executam esses procedimentos em suas rotinas clínicas, enquanto 138 (77,1\%) deles não. Dentre os tipos de procedimentos elencados no questionário, a aplicação de toxina botulínica com finalidade funcional foi a intervenção mais executada pelos participantes - 24,1\% (41) e a rinomodelação - 8 (4,7\%) a menos executada (Figura 3). 
Figura 3. Procedimentos de HOF executados no consultório odontológico. (N=170).

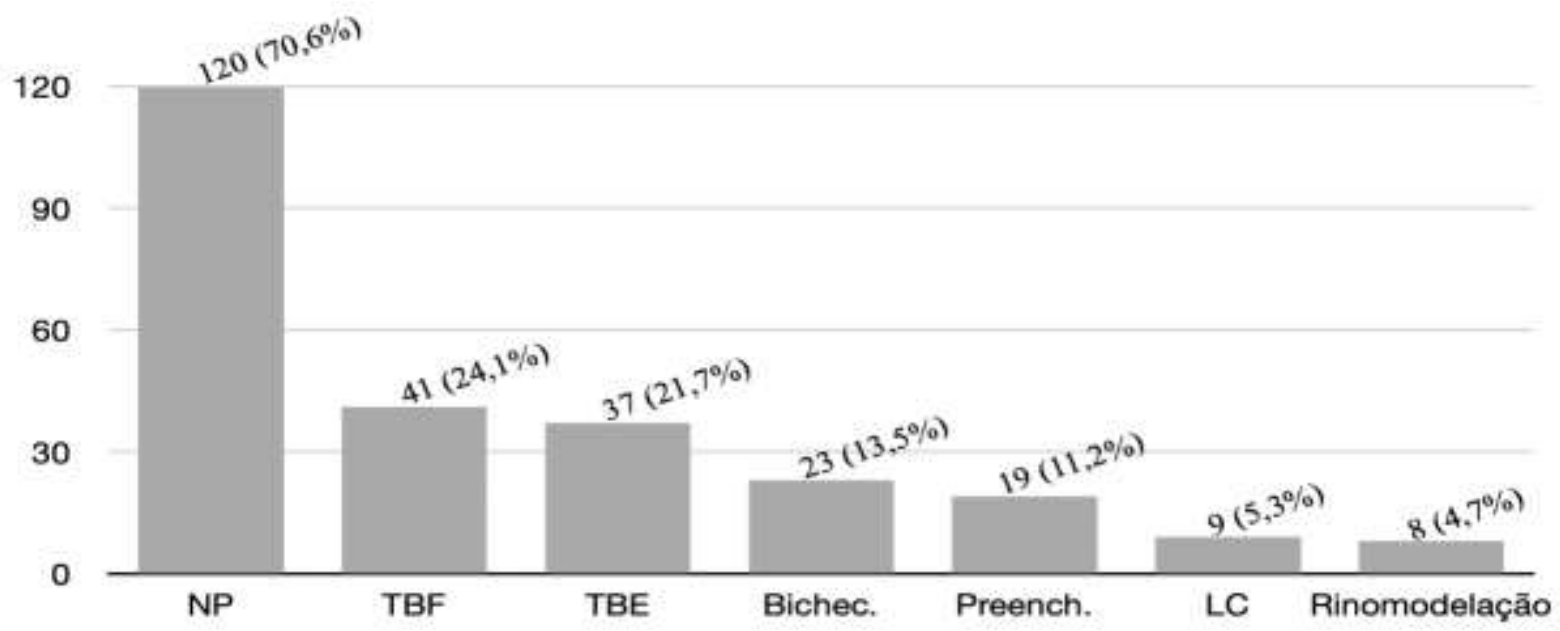

Legenda: NP: nenhum dos procedimentos descritos; TBF: toxina botulínica em procedimentos funcionais; TBE: toxina botulínica em procedimentos estéticos; Bichec.: Bichectomia; Preench.: Preenchedores; LC: lipoplastia cervical. Fonte: Autores (2021).

Quando questionados sobre terem frequentado cursos de HOF, $58(33,1 \%)$ cirurgiões-dentistas afirmaram ter participado desse tipo de formação, enquanto 117 (66,9\%) não cursaram.

Dos profissionais que declararam ter frequentado esses cursos de HOF, 17 (29,3\%) deles participaram de cursos com duração de 3 dias, 16 (28,1\%) em cursos de 4 dias e 1 cirurgião-dentista afirmou ter cursado especialização de HOF, conforme Figura 4.

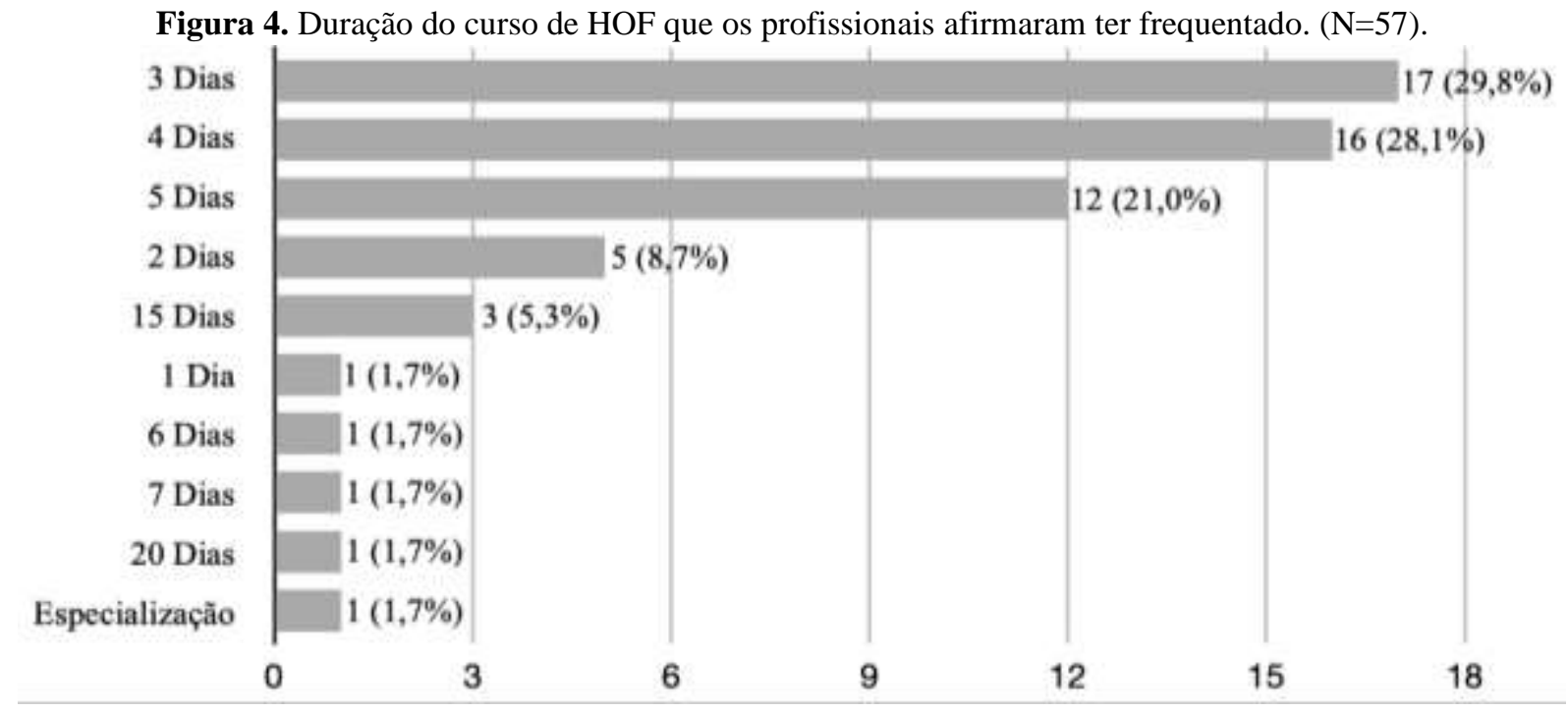

Fonte: Autores (2021).

Sobre esses cursos de HOF que os participantes relataram ter cursado, 54 (94,7\%) afirmaram ter sido abordado o tema toxina botulínica com finalidade funcional foi o mais abordado, sendo o tópico rinomodelação - 17 (29,8\%) o menos abordado (Figura 5).

Sobre a abordagem ético-legal nos cursos frequentados pelos participantes da pesquisa, $44(83,0 \%)$ deles afirmaram que o Código de Ética Odontológico (CEO) foi abordado durante as aulas, 32 (60,4\%) disseram que a Resolução do Conselho 
Federal de Odontologia 176/16 foi abordada, 18 (33,9\%) relataram a exposição da Lei no 5.081/66, 8 (15,1\%) fizeram menção ao Código de Defesa do Consumidor (CDC) e $5(8,6 \%)$ não responderam essa questão.

Figura 5. Tipos de procedimentos abordados no curso de HOF frequentado pelos participantes. $(\mathrm{N}=57)$

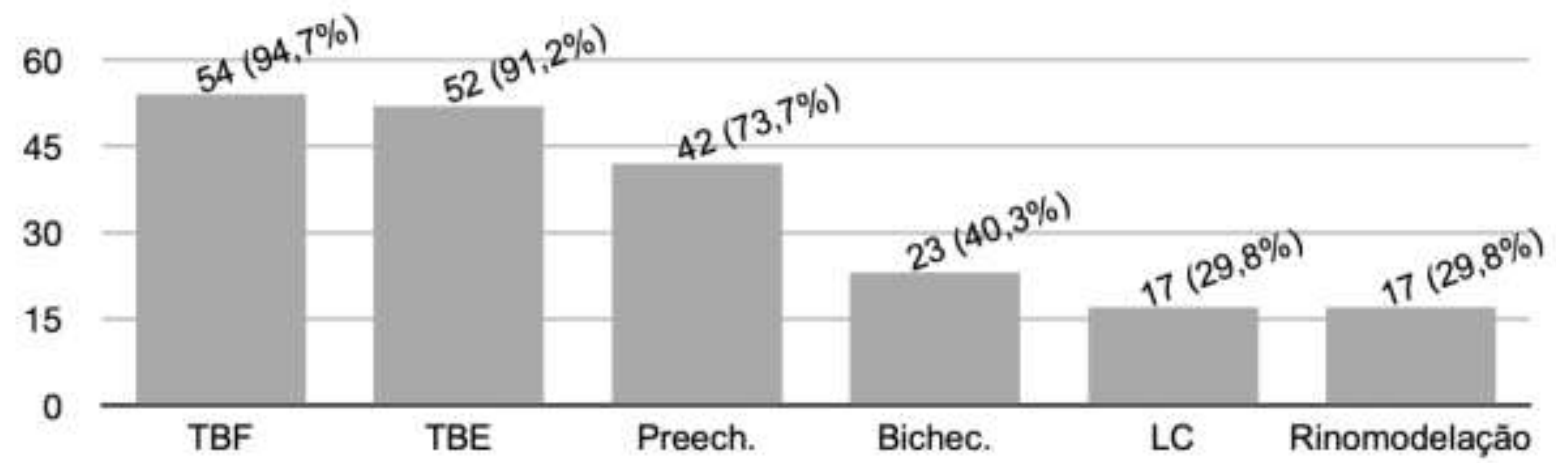

Legenda: TBF: toxina botulínica em procedimentos funcionais; TBE: toxina botulínica em procedimentos estéticos; Preench.: Preenchedores; Bichec.: Bichectomia; LC: lipoplastia cervical.

Fonte: Autores (2021).

Questionando-se sobre quais procedimentos, dos elencados nas questões como alternativa de resposta, os Cirurgiõesdentistas possuíam capacidade técnica para executar e se eles possuíam respaldo legal/normativo para realização de tais procedimentos, $162(97,0 \%)$ dos participantes afirmaram que aplicação de toxina botulínica com finalidade funcional é um procedimento que pode ser realizado devido sua aptidão, bem como 156 (91,0\%) participantes consideram os Cirurgiõesdentistas respaldados legalmente para realizar esse tipo de intervenção, sendo que 10 (5,9\%) participantes afirmaram que os Cirurgiões-dentistas não possuem respaldo legal/normativo para realização de nenhum dos procedimentos elencados nas questões (Figura 6).

Figura 6. Frequência de respostas segundo os procedimentos e a capacidade técnica do cirurgião-dentista e o respaldo legal/normativo para realizá-los.

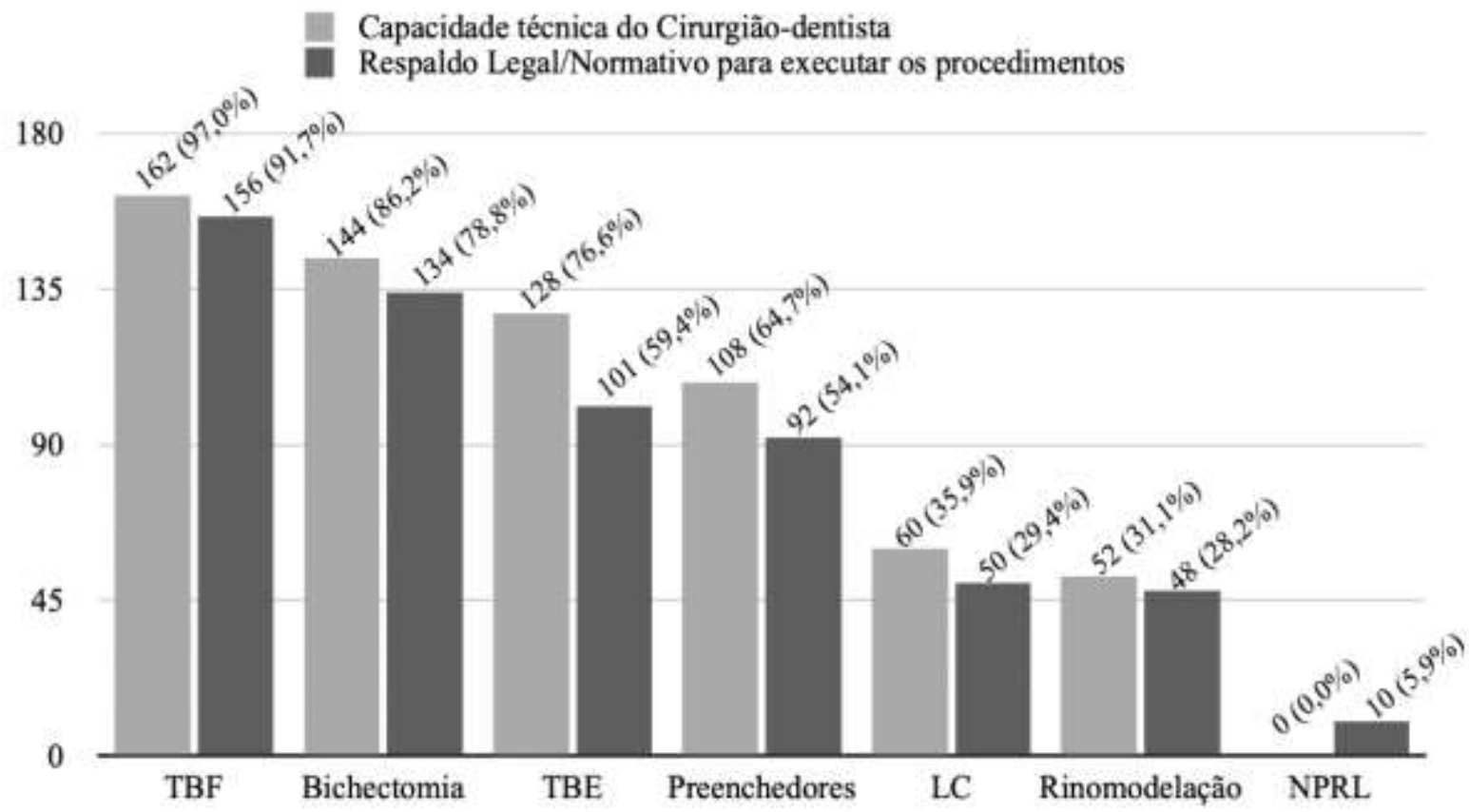

Legenda: TBF: toxina botulínica em procedimentos funcionais; TBE: toxina botulínica em procedimentos estéticos; LC: lipoplastia cervical; NPRL: não possui respaldo legal ou normativo.

Fonte: Autores (2021). 
No que diz respeito à rinomodelação, as intercorrências que podem ser mais associadas a esse tipo de procedimento, segundo os participantes da pesquisa, são Necrose nasal - 141 (82,4\%), Insatisfação quanto ao resultado final - 139 (81,3\%) (Figura 7).

Figura 7. Intercorrências que podem surgir em virtude do procedimento de Rinomodelação. $(\mathrm{N}=171)$.

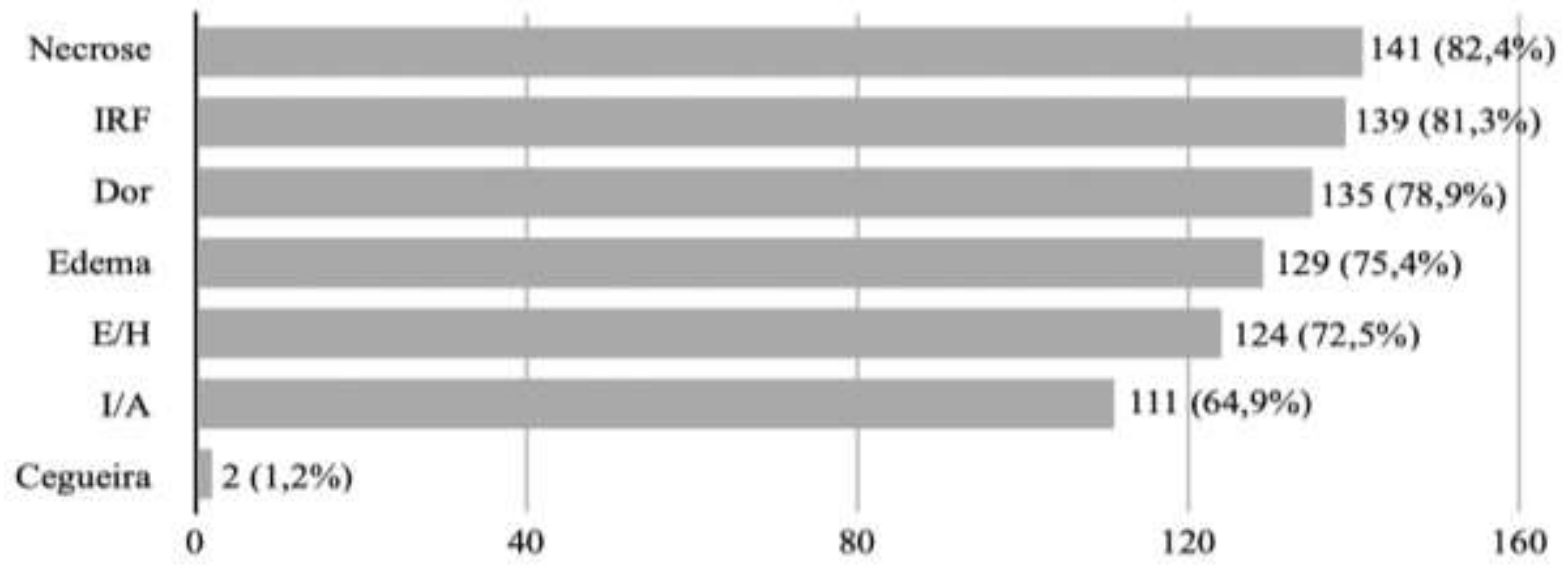

Legenda: IRF: insatisfação quanto ao resultado final; E/H: equimose ou hematoma; I/A: infecção ou abcesso; IEL: implicações éticas e legais.

Fonte: Autores (2021).

Dos profissionais que fizeram parte da pesquisa, $154(89,0 \%)$ não se sentem aptos a tratarem um quadro de necrose nasal instalado após o procedimento de rinomodelação, enquanto 19 (11,0\%) deles afirmaram serem capazes de tratar essa complicação. Dos que responderam que não tratariam a necrose nasal, perguntamos para qual profissional eles encaminhariam o paciente com necrose nasal instalada, e, 110 (72,8\%) deles encaminhariam o paciente para um Médico, 35 (23,2\%) para um cirurgião-dentista especialista em Cirurgia e Traumatologia Bucomaxilofacial e $6(4,0 \%)$ afirmaram que poderiam encaminhar tanto para um cirurgião-dentista especialista em CTBMF ou para um Médico.

Das intercorrências que podem surgir em decorrência do procedimento de bichectomia, a assimetria facial (143 $83,6 \%$ ) foi a alternativa mais relatada pelos participantes, seguida pelo rompimento do ducto parotídeo - 140 (81,9\%) (Figura $8)$. 
Figura 8. Intercorrências que podem surgir em virtude do procedimento de Bichectomia. $(\mathrm{N}=171)$.

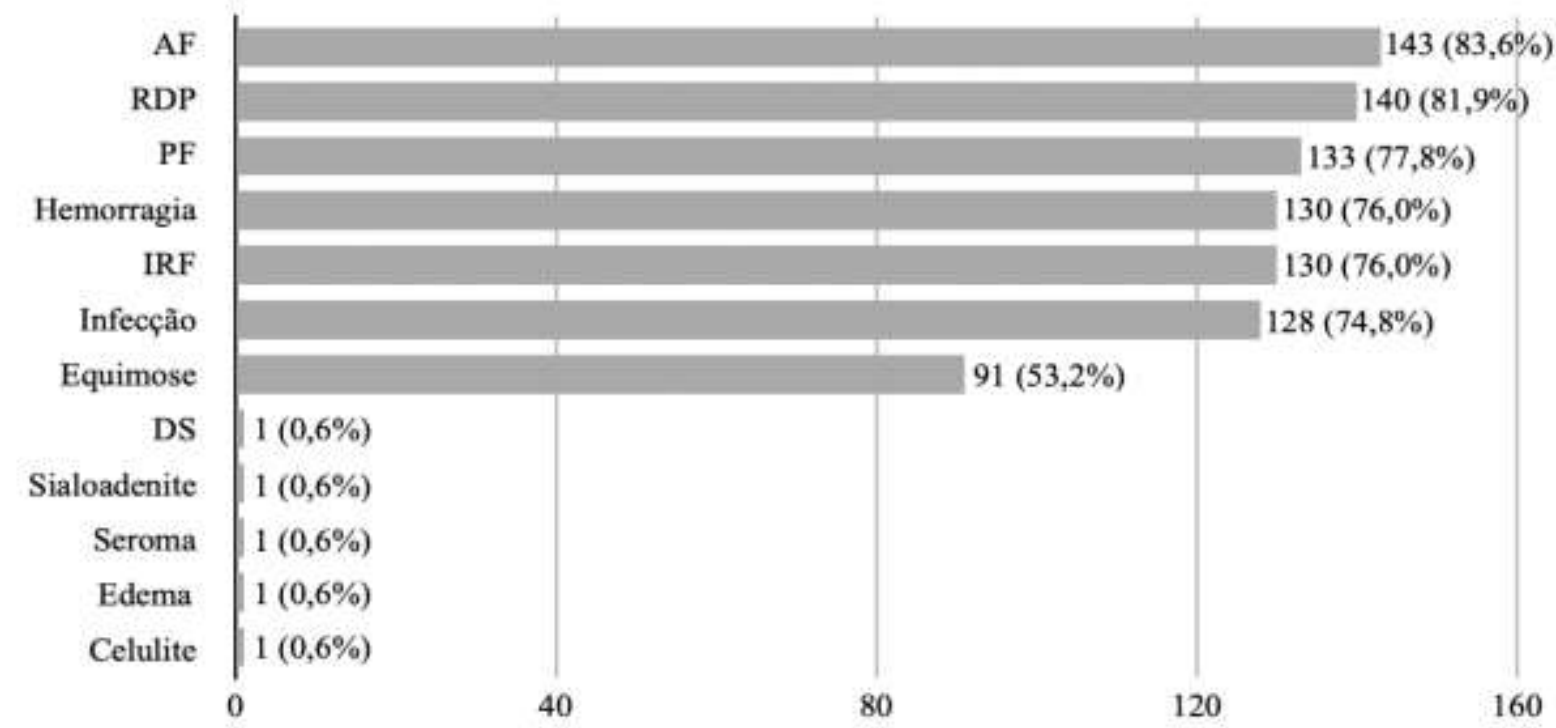

Legenda: AF: assimetria facial; RDP: rompimento do ducto parotídeo; PF: paralisia facial; IRF: insatisfação quanto ao resultado final; DS: deiscência de sutura.

Fonte: Autores (2021).

Os participantes relataram ainda estarem aptos a tratarem as seguintes intercorrências durante ou após a cirurgia de bichectomia: infecção - 107 (69,5\%), hemorragia - 106 (68,9\%), sendo que afirmaram 9 (5,8\%) desses profissionais declararam que não conseguiriam tratar nenhuma dessas intercorrências (Figura 9).

Figura 9. Intercorrências decorrentes do procedimento de Bichectomia que podem ser tratadas pelos entrevistados durante ou após o procedimento cirúrgico. $(\mathrm{N}=154)$.

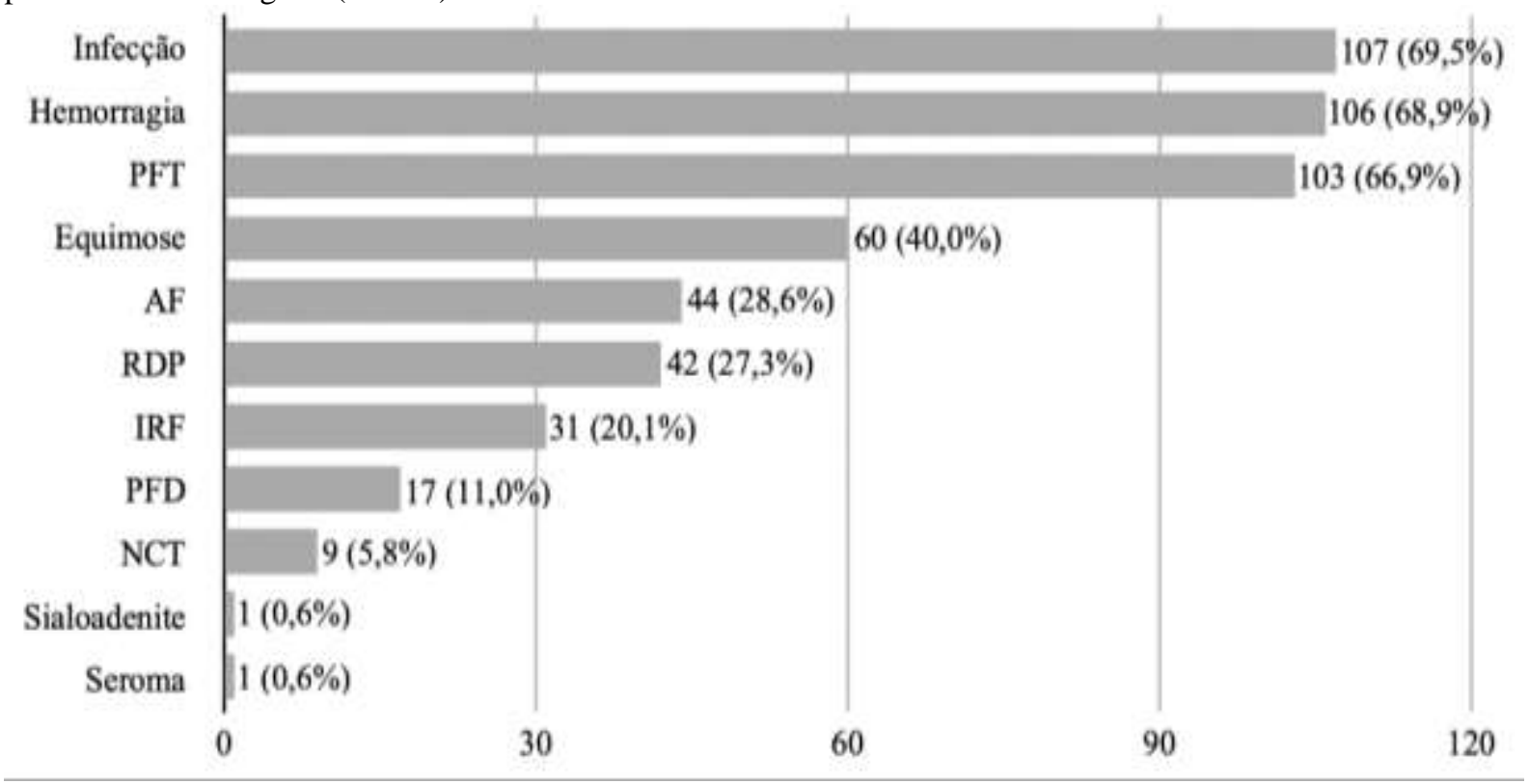

Legenda: PFT: paralisia facial temporária; AF: assimetria facial; RDP: rompimento do ducto parotídeo; IRF: insatisfação quanto ao resultado final; PFD: paralisia facial definitiva; NCT: não conseguiria tratar.

Fonte: Autores (2021). 
Com relação à associação das variáveis segundo a Tabela 1, foi possível perceber os seguintes resultados estatisticamente significantes segundo as Tabelas 3, 4, 5 e 6, sendo os demais resultados do cruzamento das variáveis suprimidos em tais tabelas.

Tabela 3. Resultado estatisticamente significante $(\mathrm{p}<0,05)$ do cruzamento da Questão 2 com as Questões 11,12 , e 16.

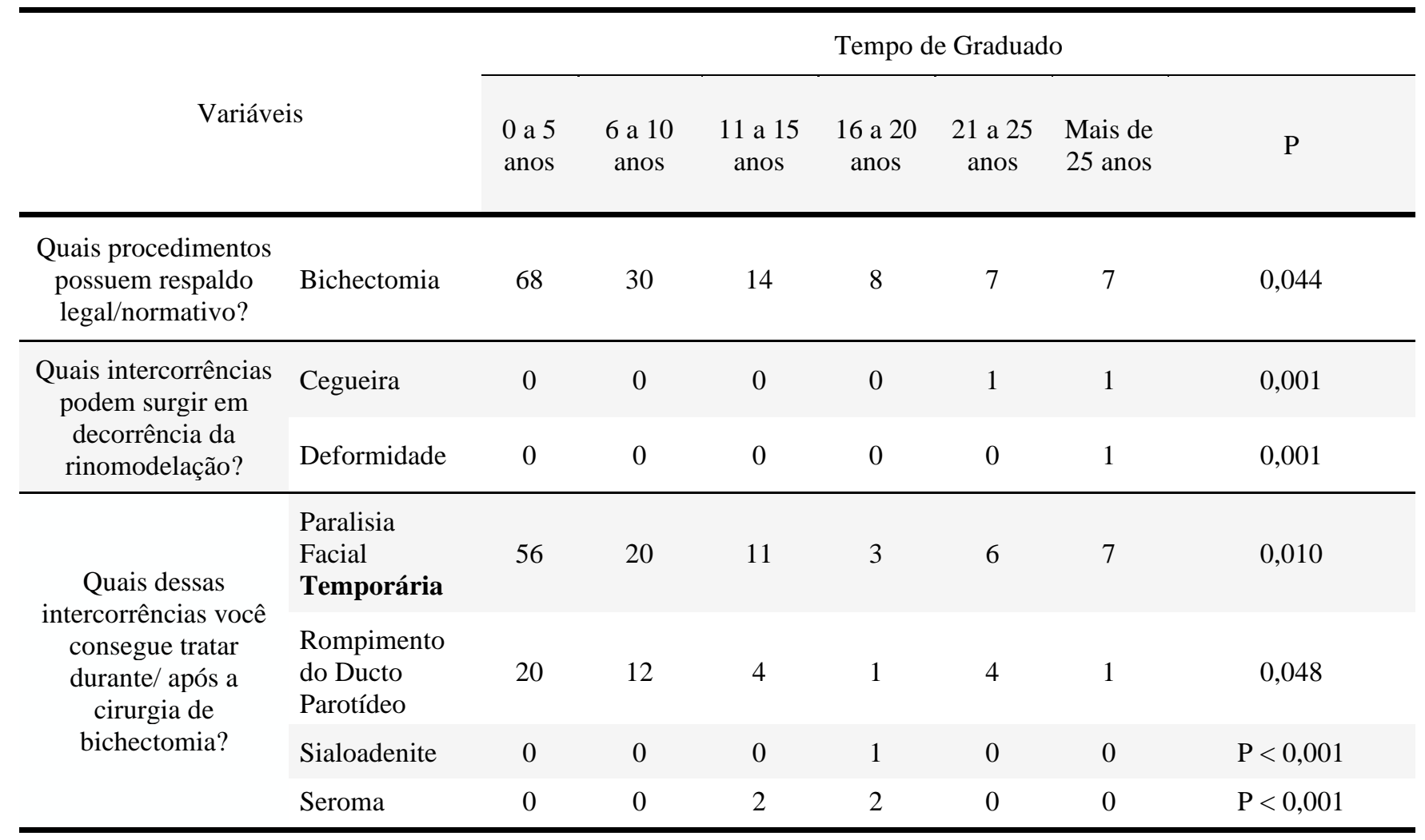

Fonte: Autores (2021). 
Tabela 4. Resultado estatisticamente significante $(\mathrm{p}<0,05)$ do cruzamento da Questão 3 com as Questões 5, 14,15 , e 16.

\begin{tabular}{|c|c|c|c|c|c|c|c|c|c|c|c|c|c|}
\hline \multirow{2}{*}{\multicolumn{2}{|c|}{ Variáveis }} & \multicolumn{12}{|c|}{ Especialidades } \\
\hline & & $\mathbf{A}$ & B & $\mathbf{C}$ & D & $\mathbf{E}$ & $\mathbf{F}$ & $\mathbf{G}$ & $\mathbf{H}$ & I & $\mathbf{J}$ & $\mathbf{K}$ & $\mathbf{P}$ \\
\hline \multirow{4}{*}{$\begin{array}{l}\text { Quais } \\
\text { procedimentos } \\
\text { você realiza no } \\
\text { consultório? }\end{array}$} & $\begin{array}{l}\text { Toxina Botulínica - } \\
\text { Estética }\end{array}$ & 3 & 9 & 3 & 7 & 6 & 1 & 3 & 1 & 0 & 2 & 1 & 0,048 \\
\hline & $\begin{array}{l}\text { Toxina Botulínica - } \\
\text { Funcional }\end{array}$ & 4 & 11 & 3 & 7 & 8 & 1 & 2 & 1 & 0 & 2 & 1 & 0,004 \\
\hline & Bichectomia & 6 & 1 & 0 & 2 & 7 & 0 & 2 & 1 & 0 & 1 & 2 & 0,001 \\
\hline & Rinomodelação & 0 & 2 & 0 & 1 & 2 & 0 & 0 & 0 & 0 & 2 & 0 & $\mathrm{P}<0,001$ \\
\hline \multirow{3}{*}{$\begin{array}{c}\text { Em caso de } \\
\text { complicação na } \\
\text { rinomodelação, } \\
\text { para quem } \\
\text { você } \\
\text { encaminharia o } \\
\text { paciente? }\end{array}$} & Médico & 6 & 20 & 15 & 25 & 5 & 0 & 18 & 5 & 7 & 0 & 4 & $\mathrm{P}<0,001$ \\
\hline & $\begin{array}{l}\text { Cirurgião-dentista } \\
\text { especialista em } \\
\text { CTBMF }\end{array}$ & 2 & 2 & 6 & 9 & 8 & 0 & 6 & 2 & 1 & 0 & 1 & $\mathrm{P}<0,001$ \\
\hline & $\begin{array}{l}\text { Cirurgião-dentista } \\
\text { especialista em } \\
\text { CTBMF ou Médico }\end{array}$ & 0 & 0 & 0 & 2 & 1 & 1 & 2 & 0 & 0 & 0 & 0 & $\mathrm{P}<0,001$ \\
\hline \multirow{2}{*}{$\begin{array}{c}\text { Quais } \\
\text { intercorrências } \\
\text { podem surgir } \\
\text { em decorrência } \\
\text { da } \\
\text { bichectomia? }\end{array}$} & Infecção & 11 & 15 & 9 & 32 & 13 & 1 & 23 & 5 & 6 & 1 & 6 & 0,036 \\
\hline & Equimose & 9 & 9 & 5 & 24 & 9 & 1 & 14 & 3 & 2 & 1 & 5 & 0,028 \\
\hline \multirow{3}{*}{$\begin{array}{l}\text { Quais dessas } \\
\text { intercorrências } \\
\text { você consegue } \\
\text { tratar durante/ } \\
\text { após a cirurgia } \\
\text { de } \\
\text { bichectomia? }\end{array}$} & Assimetria Facial & 7 & 4 & 4 & 9 & 8 & 0 & 4 & 2 & 0 & 1 & 0 & 0,043 \\
\hline & Infecção & 9 & 6 & 7 & 26 & 13 & 0 & 19 & 5 & 7 & 2 & 3 & 0,015 \\
\hline & Equimose & 8 & 3 & 4 & 12 & 9 & 0 & 8 & 2 & 2 & 2 & 3 & 0,049 \\
\hline
\end{tabular}

Legenda: A: CTBMF; B: Dentística C: Prótese; D: Ortodontia; E: Implante; F: Dor Orofacial e DTM; G: Clínico Geral; H: Endodontia; I: Periodontia; J: HOF - Harmonização Orofacial; K: Outras; P: Valor de P.

Fonte: Autores (2021). 
Tabela 5. Resultado estatisticamente significante $(\mathrm{p}<0,05)$ do cruzamento da Questão 4 com as Questões 5 e 14.

\begin{tabular}{|c|c|c|c|}
\hline & \multirow{2}{*}{ Variáveis } & \multicolumn{2}{|c|}{$\begin{array}{l}\text { Realiza procedimentos de } \\
\text { Harmonização Orofacial }\end{array}$} \\
\hline & & Sim & $\mathrm{P}$ \\
\hline \multirow{6}{*}{$\begin{array}{l}\text { Quais procedimentos você } \\
\text { realiza no consultório? }\end{array}$} & Toxina Botulínica - Funcional & $37(90,2 \%)$ & \multirow{6}{*}{$\mathrm{P}<0,001$} \\
\hline & Toxina Botulínica - Estética & $35(85,4 \%)$ & \\
\hline & Preenchedores & $18(43,9 \%)$ & \\
\hline & Bichectomia & $17(41,5 \%)$ & \\
\hline & Lipoplastia cervical & $9(22,0 \%)$ & \\
\hline & Rinomodelação & $7(17,1 \%)$ & \\
\hline \multirow{3}{*}{$\begin{array}{l}\text { Em caso de complicação na } \\
\text { rinomodelação, para quem } \\
\text { você encaminharia o } \\
\text { paciente? }\end{array}$} & Médico & $19(46,3 \%)$ & \multirow{3}{*}{0,010} \\
\hline & $\begin{array}{l}\text { Cirurgião-dentista especialista em } \\
\text { CTBMF }\end{array}$ & $7(17,1 \%)$ & \\
\hline & $\begin{array}{l}\text { Cirurgião-dentista especialista em } \\
\text { CTBMF ou Médico }\end{array}$ & $2(4,9 \%)$ & \\
\hline
\end{tabular}

Fonte: Autores (2021).

Tabela 6. Respostas da Questão 16 apenas para os profissionais que afirmaram realizar o procedimentos de bichectomia em sua rotina clínica. $(\mathrm{N}=23)$.

\begin{tabular}{|c|c|c|c|}
\hline & \multirow{2}{*}{ Variáveis } & \multicolumn{2}{|c|}{$\begin{array}{c}\text { Executa bichectomia em sua rotina } \\
\text { clínica }\end{array}$} \\
\hline & & Sim & $\mathrm{P}$ \\
\hline \multirow{10}{*}{$\begin{array}{c}\text { Quais das intercorrências } \\
\text { você entende que consegue } \\
\text { tratar durante/após a cirurgia } \\
\text { de bichectomia? }\end{array}$} & Hemorragia & $21(91,3 \%)$ & $\mathrm{P}<0,001$ \\
\hline & Infecção & $21(91,3 \%)$ & $\mathrm{P}<0,001$ \\
\hline & Paralisia Facial Temporária & $18(78,2 \%)$ & 0,001 \\
\hline & Equimose & $16(69,5 \%)$ & $\mathrm{P}<0,001$ \\
\hline & Assimetria Facial & $10(43,5 \%)$ & 0,001 \\
\hline & Rompimento do Ducto Parotídeo & $9(39,1 \%)$ & 0,001 \\
\hline & Insatisfação quanto ao resultado final & $5(21,7 \%)$ & 0,005 \\
\hline & Paralisia Facial Definitiva & $2(8,7 \%)$ & 0,005 \\
\hline & Sialoadenite & $1(4,3 \%)$ & 0,007 \\
\hline & Seroma & $1(4,3 \%)$ & 0,007 \\
\hline
\end{tabular}

Fonte: Autores (2021). 


\section{Discussão}

Atualmente a Odontologia busca, além do restabelecimento da função mastigatória, viabilizar a harmonia estética dos terços da face, não só com procedimentos relacionados à ortodontia ou cirurgias ortognáticas (Brasil, Res. CFO - 063, 2005; Ribas, et al., 2005), mas também com procedimentos estéticos, que até 2011 eram realizados apenas por profissionais médicos. Tal fato vem dividindo opiniões sobre a atuação do cirurgião-dentista em procedimentos de Harmonização Orofacial (HOF), questionando ainda sobre a habilitação, respaldo legal e possível invasão da área médica pelos cirurgiões-dentistas e outros profissionais da área de saúde (biomédicos, farmacêuticos, biólogos, etc).

Sendo assim, a presente pesquisa buscou conhecer o perfil dos participantes, que, em sua maioria, reportaram as especialidades de Ortodontia (49) e Implantodontia (33). Dois cirurgiões-dentistas declararam ser especialistas em HOF, entretanto, na época da coleta de dados a especialidade de Harmonização Orofacial ainda não havia sido reconhecida e legalizada pelo CFO, fato que ocorreu em janeiro de 2019 por meio da Resolução CFO - 198 (Brasil, Res. CFO - 198, 2019). Consequentemente, comete falta ética o profissional que, mesmo que tenha formação acadêmica e diploma de conclusão de especialidade, se intitule e/ou anuncie ser especialista sem que esteja devidamente inscrito no CRO (Brasil, Art. 24; Art. 32, inciso IV; Art 44, inciso II - CEO, 2012), e nesse caso, nem a especialidade havia sido reconhecida ainda.

Sobre a participação dos cirurgiões-dentistas em cursos de HOF, 58 (33,1\%) deles frequentaram algum curso, e, 41 $(22,9 \%)$ desses profissionais afirmaram que realizam procedimentos de HOF em sua rotina clínica. Contudo, dois desses profissionais que realizam procedimentos de HOF não frequentaram cursos de capacitação, segundo suas respostas ao questionário. Tal fato, do ponto de vista clínico, além de oferecer maiores chances de intercorrências ao paciente (Tamura, 2013; Nassif, et al., 2015; Parada, et al., 2016) incorre em falta ética uma vez que o profissional exerce atividades para as quais não estaria devidamente capacitado (Brasil, Art 11, inciso V; Art 53, inciso IX - CEO, 2012), e, não se preocupa em manter seus conhecimentos atualizados e trabalhar de forma a conseguir contornar intercorrências graves, circunstância em que a profissão possa ser maculada perante a sociedade perante a grande visibilidade no cenário atual da saúde (Brasil, Art $9^{\circ}$, inciso III, inciso IV - CEO, 2012).

Ainda sobre os cursos de HOF que os participantes relataram ter cursado, 8 (15,1\%) afirmaram que o Código de Defesa do Consumidor (CDC) (Brasil, Lei no 8.078 - CDC, 1990) foi abordado, 18 (33,9\%) a Lei no 5.081/66 (Brasil, Lei $n^{\circ}$ 5.081, 1966), 31 (60,4\%) a Resolução CFO - 176/2016 (Brasil, Res. CFO - 176, 2016) e 44 (83,0\%) o Código de Ética Odontológica (CEO) (Brasil, Res. CFO - 118 - CEO, 2012). Os profissionais afirmaram ainda que foram abordados os seguintes temas nesses cursos: aplicação de toxina botulínica, utilização de preenchedores faciais, cirurgia de bichectomia, lipo de papada e rinomodelação; e, conforme a Resolução CFO - 198/2019, tais procedimentos estão incluídos no rol intervenções pertinente a cirurgiões-dentistas especialistas em HOF (Brasil, Lei nº 5.081, 1966; Brasil, Res. CFO - 198, 2019).

A abordagem de tais normativas nos cursos de capacitação em HOF é, sem dúvida, de fundamental importância para o estabelecimento de regras e condutas para sua prática em Odontologia. Confrontando as respostas dos participantes, relativas às questões sobre capacidade técnica para executar procedimentos e possuir o respaldo legal/normativo para execução dos procedimentos de HOF, é possível perceber uma compatibilidade entre tais respostas, pois os profissionais se manifestam muito favoráveis à presença de capacidade técnica e respaldo para aplicação de toxina botulínica com finalidade estética e funcional, realização de bichectomia e preenchedores faciais, referindo-se ainda à lipo de papada e rinomodelação como procedimentos os quais o cirurgião-dentista apresentaria menos competência para executar.

Do ponto de vista clínico a bichectomia e a rinomodelação, apesar de serem considerados procedimentos simples e corriqueiros, possuem riscos significativos, em decorrência das estruturas anatômicas que são manipuladas para a realização dessas intervenções (Ahari, et al., 2019; Hong, et al., 2019). Contudo a atuação do cirurgião-dentista deve sempre estar balizada por normativas, e sendo assim, a Res. CFO - 198/2019 (Brasil, Res. CFO - 198, 2019) regulamentou a atuação dos 
cirurgiões-dentistas em procedimentos de HOF, e, juntamente com a Res. CFO - 176/2016 (Brasil, Res. CFO - 176, 2016) estipulou a área de atuação desses profissionais. Dessa forma, a Res. CFO - 176/2016 não foi capaz de esclarecer o que vem a ser "estruturas anexas afins", o que nos faz refletir que, sobre o procedimento de rinomodelação, embora seja realizada com a técnica de infiltração de materiais preenchedores, o procedimento em si não está descrito no rol de tratamentos que podem ser realizados pelos cirurgiões-dentistas.

Com o intuito de esclarecer a expressão "áreas afins” constante no Art 3º da Res. CFO - 198/2019, pois alguns cirurgiões-dentistas estavam se valendo de interpretações diversas para realizar procedimentos que não são liberados como prática odontológica, o CFO regulamentou a Res. CFO - 230 em agosto de 2020, sendo um dos objetivos de tal normativa proibir aos cirurgiões-dentistas a realização de procedimentos como alectomia e rinoplastia (Brasil, Res. CFO - 230, 2020), ambos executados no nariz com finalidade estética. Corroborando essa consideração, ainda, a Res. CFO - $063 / 2005$ (Brasil, Art 43 - Res. CFO- 063, 2005) relata ser vedado ao cirurgião-dentista a prática de cirurgia estética, ressalvadas as esteticofuncionais do aparelho mastigatório, do qual o nariz não faz parte. Além do mais, caso ocorra alguma complicação referente aos procedimentos já mencionados, é de competência médica a realização de revascularização, cirurgias para restabelecimento de feixe nervoso, bem como a realização de cirurgia com retalho de pele para reabilitação de necrose nasal (Brasil, Art 47 e Art 48 - Res. CFO - 063, 2005), e, sendo assim, é sugerido que procedimentos que envolvam estética continuem sendo de competência médica.

Ainda, no que tange a legislação, é importante ressaltar que mesmo que as lesões traumáticas, decorrentes de procedimentos de HOF ou não, venham a ser diagnosticadas por um terceiro profissional, a responsabilidade por provocar a lesão não pode ser transferida a outros profissionais (Brasil, Art 129 - CP, 1940). Além disso, existe a necessidade de indenização ao paciente quando, no exercício da profissão, o profissional causar lesão, agravar-lhe o mal ou inabilitar o paciente ao trabalho (Brasil, Art 951 - CC, 2002), fatos que podem acontecer quando há complicações de procedimentos como bichectomia ou rinomodelação, por exemplo.

Todo e qualquer procedimento odontológico possui riscos, principalmente os inerentes à resposta biológica de cada paciente (Tamura, 2013; Parada, et al., 2016). Dessa forma, o cirurgião-dentista tem por obrigação elaborar um Termo de Consentimento Livre e Esclarecido (TCLE) explicitando as vantagens, desvantagens, riscos, benefícios e limitações do caso clínico que será tratado, para que, por meio de tal documento, o paciente possa dirimir suas dúvidas e tomar conhecimento de possíveis complicações que possam acontecer, bem como as ações que serão realizadas caso as intercorrências sejam instaladas. O TCLE, além de ser um dos documentos que fazem parte do prontuário odontológico que asseguram a compreensão e anuência do paciente ao tratamento proposto que será executado (Brasil, Art 9º, inciso X; Art 11, inciso X; Art 17 - CEO, 2012), sendo que incorre em falta ética a sua não elaboração, fazendo com que os profissionais exponham-se a conflitos éticos e cíveis (Rodrigues, et al., 2017). Além disso, uma análise realizada por Rayess, et al (2018) mostrou que o maior índice de litígios associados à preenchedores faciais e cegueira se deu devido à aplicação do TCLE e a comunicação entre o profissional e paciente não terem sido efetivas em esclarecer sobre potenciais complicações (Rayess, et al., 2018).

O eventual surgimento de complicações nos procedimentos realizados por cirurgiões-dentistas deve ser resolvido pelo próprio profissional ou suceder com o encaminhamento do paciente a outros profissionais para realização de novos tratamentos que visem amenizar e/ou sanar os problemas causados pelas complicações. O encaminhamento do paciente a outro profissional, por meio de documento próprio, não é caracterizado como abandono ou descontinuidade do tratamento que está em andamento, e, sendo assim, o paciente sempre estará aos cuidados de algum profissional, seja cirurgião-dentista ou médico (Brasil, Art 11, inciso VI - CEO, 2012). O profissional que encaminha o paciente pode adotar uma conduta cordial e acompanhar a evolução do tratamento, mesmo que não seja mais sua responsabilidade, demonstrando zelo ao paciente. 
A relação entre a classificação da bichectomia ter respaldado legal/normativo para ser executada por cirurgiõesdentistas e os participante formados há menos tempo (Tabela 3) pode ser explicada pelo conhecimento prévio em cursos de graduação sobre o procedimento estético em questão, já que essa cirurgia passou a ser mais abordada e discutida a partir de 2011, quando a odontologia começou de fato a permear com maior intensidade os procedimentos de HOF com a liberação da utilização de preenchedores faciais e toxina botulínica com finalidade estética (Brasil, Res. CFO - 112, 2011; Brasil, Res. CFO - 176, 2016). Mais do que um procedimento unicamente estético, a cirurgia de bichectomia deve ser abordada com cautela, uma vez que a remoção dessa peça anatômica pode impossibilitar o cirurgião-dentista de reconstruir facilmente defeitos orais de pequeno a médio porte, como um acidente de comunicação bucosinusal por exemplo (Manelli, et al., 2018). Sendo assim, é importante a realização de uma boa anamnese antes da cirurgia de bichectomia, observando atentamente se o paciente já foi submetido a exodontia de terceiros molares, por exemplo (Papazian, et al., 2018).

Em relação às intercorrências que podem estar associadas à rinomodelação (Tabela 3), apesar de apenas dois cirurgiões-dentistas afirmarem que as intercorrências cegueira e deformidade podem acontecer, esse é um quadro de relativa incidência e que promove mais sequelas do que o aparecimento de equimose e/ou edema. Uma vez diagnosticados eventos adversos da rinomodelação executada com ácido hialurônico, existe um protocolo para condução do caso, que envolve terapias locais como aplicação de calor, laser e massagem, utilização de medicamentos como antibióticos e antiinflamatórios e aplicação de hialuronidase (Prado \& Rodríguez-Feliz, 2017; Dal Lago \& Kapczinski, 2020). A perda de visão pode ocorrer, mais frequentemente, quando o preenchedor - ácido hialurônico - é infiltrado em áreas como nariz, glabela e testa, sendo fundamental o diagnóstico precoce do tipo de bloqueio ocasionado para um melhor prognóstico. Sendo que a perda parcial da visão tem um prognóstico melhor de recuperação do sentido do que a perda completa da visão (Kapoor, et al., 2019; Sito, et al., 2019; Ortiz, et al., 2020).

Confrontando as especialidades dos participantes e os procedimentos de HOF que eles realizam (Tabela 4) é possível perceber que a aplicação de toxina botulínica, tanto com finalidade funcional quanto estética, são procedimentos realizados majoritariamente por profissionais especialistas em dentística e ortodontia, o que pode ser explicado pela relação entre melhores resultados estéticos de seus tratamentos dentais quando associados a procedimentos em tecidos moles relacionados. Um exemplo fácil de ser compreendido é a aplicação de toxina botulínica em lábio superior para redução de sorriso gengival, que é muito utilizado em associação a finalização de tratamento ortodôntico e reabilitação com facetas ou laminados cerâmicos (Matos, et al., 2017).

Já as especialidades com maior atuação em procedimentos de bichectomia (Tabela 4) são a implantodontia e a cirurgia e traumatologia bucomaxilofacial, fato que pode ser explicado pela atividade e familiaridade desses profissionais com procedimentos cirúrgicos. Sendo a infecção e a equimose as intercorrências mais associadas a esse tipo de tratamento, segundo a especialidade de ortodontia e os clínicos gerais (Tabela 4). Apesar de apenas dois profissionais especialistas em ortodontia afirmarem que realizam bichectomia em sua prática clínica, é controverso o fato de os demais especialistas em ortodontia se sentirem aptos a tratar intercorrências resultantes da bichectomia já que não realizam tal procedimento (Tabela 4). Dos profissionais que executam essa cirurgia em sua rotina clínica, era esperado que todos respondessem que estão muito bem preparados para lidar com as intercorrências que podem acontecer. Contudo, a maioria desses profissionais consideram-se aptos para solucionar hemorragias e infeções decorrentes da bichectomia (Tabela 6).

A respeito da bichectomia, foi possível observar que os participantes da pesquisa entendem que cirurgiões-dentistas possuem capacidade técnica $(144$ - 86,2\%) e respaldo normativo (134 - 78,8\%) para execução desse tipo de cirurgia, informação que tornou-se verdadeira a partir da regulamentação das atividades do especialista em HOF segundo a Res. CFO 198/2019 (Brasil, Res. CFO - 198, 2019). Entretanto, como todo procedimento cirúrgico, a bichectomia pode apresentar complicações irreversíveis para as quais o cirurgião-dentista não esteja preparado para lidar como a paralisia facial definitiva e 
o rompimento do ducto parotídeo (Vieira, et al., 2019). No caso de rompimento do ducto pode-se lançar mão de uma cirurgia plástica para que esse ducto não seja obliterado passando a desembocar mais posteriormente da região anatômica do ducto, que, como toda cirurgia plástica, deverá ser realizada por um Médico (Brasil, Art 47 e Art 48 - Res. CFO - 063, 2005).

A rinomodelação é o procedimento mais executado por especialistas em dentística, implantodontia e por aqueles que se intitulavam especialistas em HOF (Tabela 4) e, de forma geral, o procedimento menos realizado entre todos os profissionais participantes da pesquisa que realizam HOF em sua prática clínica (Tabela 5). Entretanto, ao questionarmos para quem esses participantes encaminhariam um paciente que apresentasse complicações na rinomodelação a maior resposta, em todas as categorias de especialidades (Tabela 4) e dentre os profissionais que tem prática clínica recorrente em HOF (Tabela 5), foi o encaminhamento a um médico. Essa afirmação corrobora o fato de os próprios cirurgiões-dentistas perceberem que não são aptos a tratarem complicações de rinomodelação, principalmente as que necessitam de cirurgias estéticas.

Em casos de necrose nasal, onde é necessário intervenção cirúrgica para restabelecimento anatômico, o profissional que deve atuar nesse quadro é o médico, uma vez que cirurgias estéticas e que necessitem de enxertos de áreas doadoras que se encontram fora da área bucomaxilofacial devem ser realizadas exclusivamente por esses profissionais (Brasil, Art 47 e Art 48 - Res. CFO - 063, 2005). Sendo assim, não basta que o profissional tenha conhecimento sobre anatomia facial, ele deve ser capaz de indicar e administrar os preenchedores (Beauvais \& Ferneini, 2019) de forma correta e contornar situações de intercorrências imediatas ou tardias seja elas leves ou graves. Mesmo que não haja vedação para realização da rinomodelação pelo cirurgião-dentista, é de bom tom que esses profissionais atuem apenas em casos que consigam tratar efetivamente todo e qualquer tipo de intercorrência relacionado aos procedimentos, ou seja, os cirurgiões-dentistas não deveriam realizar rinomodelação.

\section{Conclusão}

De acordo com a pesquisa realizada foi possível constatar que os participantes acreditam que cirurgiões-dentistas possuem capacidade técnica e respaldo legal/normativo para realização de procedimentos de Harmonização Orofacial, sendo a aplicação de toxina botulínica com finalidade funcional e a realização da cirurgia de bichectomia as intervenções que esse profissionais realizam com maior propriedade, e, a rinomodelação o procedimento menos aceito para a prática clínica do cirurgião-dentista. Diante de uma possível complicação da rinomodelação, 110 (72,8\%) participantes afirmaram que encaminhariam a um médico o paciente que apresentasse necrose nasal. Isso sugere que apesar de não haver impedimento na realização da rinoplastia, é importante que os cirurgiões-dentistas reflitam sobre a realização de um procedimento para o qual não estejam e não sejam plenamente capazes de intervir, principalmente se a intercorrência evoluiu para um quadro em que necessite da realização de uma cirurgia reparadora.

O mesmo ocorre com a bichectomia, uma vez que os cirurgiões-dentistas relataram não se considerar aptos a tratar a maioria das complicações passíveis de ocorrer. Diante dessa realidade é importante ressaltar que comete falta ética o profissional que executa qualquer procedimento/tratamento para o qual não esteja devidamente capacitado, podendo ainda responder criminalmente pelas lesões, decorrente de complicações, causadas ao paciente, ficando o profissional obrigado a proceder com a reparação do dano. Perante aos resultados obtidos no presente estudo sugere-se o aprofundamento investigativo com relação aos riscos clínicos e aspectos ético e legais dos demais procedimentos realizados por cirurgiões-dentistas na Harmonização Orofacial.

\section{Referências}

Ahari, U. Z., Eslami, H., Falsafi, P., Baramian, A., \& Maleki, S. (2016). The buccal fat pad: Importance and function. Journal of Dental and Medical Sciences, $15(60), 79-8$. 
Alvarez, G. S., \& Siqueira, E. J. (2018). Bichectomia: sistematização técnica aplicada a 27 casos consecutivos. Rev Bras Cir Plást, 33 (1), $74-81$.

Beauvais, D., \& Ferneini, E. M. (2020). Complications and litigation associated with injectable facial fillers: a cross-sectional study. J Oral Maxillofac Surg, 78 (1), 133-140.

Benjamin, M., \& Reish, R. G. (2018). Buccal fat pad excision: Proceed with caution. Plást Reconst Surg Glob Open, 6 (10), e1970.

Brasil. Código Civil. Lei nº10.406 de 10 de janeiro de 2002. http://www.planalto.gov.br/ccivil_03/leis/2002/110406.htm

Brasil. Código de Defesa do Consumidor. Lei n 8.078 de 11 de dezembro de 1990. http://www.planalto.gov.br/ccivil_03/leis/18078.htm

Brasil. Código de Ética Odontológica. Resolução CFO - 118, de 11 de maio de 2012. http://cfo.org.br/website/wp-content/uploads/2018/03/codigo_etica.pdf

Brasil. Código Penal. Decreto-Lei no 2.848 de 7 de dezembro de 1940. http://www.planalto.gov.br/ccivil_03/decreto-lei/del2848compilado.htm

Brasil. Conselho Federal de Odontologia. Resolução $N^{o}$ 230, de 14 de agosto de 2020. Regulamenta o artigo $3^{\circ}$, da Resolução CFO - 198/2019. http://sistemas.cfo.org.br/visualizar/atos/RESOLU\%c3\%87\%c3\%83O/SEC/2020/230

Brasil. Conselho Federal de Odontologia. Resolução No 176, de 06 de setembro de 2016. Revoga as Resoluções CFO - 112/2011, 145/2014 e 146/2014, referentes à utilização da toxina botulínica e preenchedores faciais, e aprova outra em substituição. http://sistemas.cfo.org.br/visualizar/atos/RESOLU\%c3\%87\%c3\%83O/SEC/2016/176

Brasil. Conselho Federal de Odontologia. Resolução $N^{\circ} 198$, de 29 de janeiro de 2019. Reconhece a Harmonização Orofacial como especialidade odontológica, e dá outras providências. http://sistemas.cfo.org.br/visualizar/atos/RESOLU\%c3\%87\%c3\%83O/SEC/2019/198

Brasil. Lei $N^{o}$ 5.081, de 24 de agosto de 1966. Regula o exercício da Odontologia. Disponível em: http://www.planalto.gov.br/ccivil_03/leis/L5081.htm

Brasil. Resolução CFO - 063/2005, atualizada em julho de 2012. http://cfo.org.br/website/wp-content/uploads/2019/01/Consolida\%C3\%A7\%C3\%A3o-dasNormas-para-Procedimentos-nos-Conselhos-Regionais.pdf

Chatrath, V., Banerjee, P. S., \& Rahman, E. (2019). Soft-tissue filler-associated blindness: A systematic review of case reports and case series. Plást Reconst Surg Glob Open, 7 (4), e2173.

Chen, Q., Liu, Y., \& Fan, D. (2016). Serious vascular complications after nonsurgical rhinoplasty: A case report. Plást Reconst Surg Glob Open, 4 (4), e683.

Coimbra, D. D., Oliveira, B. S., \& Uribe, N. C. (2015). Preenchimento nasal com novo ácido hialurônico: série de 280 casos. Surg Cosmet Dermatol, 7 (4), $320-326$.

Crocco, E. I., Alves, R. O., \& Alessi, C. (2012). Eventos adversos do ácido hialurônico injetável. Surg Cosmet Dermatol, 4 (3), $259-263$.

Dal Lago, A. C., \& Kapczinski, M. P. (2020). Manejo clínico dos efeitos adversos da utilização do ácido hialurônico no preenchimento facial. Rev Assoc Paul Cir Dent, 74 (4), 306-313.

Erbguth, F. J. (2008). From poison to remedy: the chequered history of botulium toxin. J Neural Transm (Vienna), 115 (1), $559-65$.

Fadanelli, R. G., Terres, M., Bins-Ely, P., \& Chem, R. C. (2007). Reconstrução de nariz após necrose por injeção de polimetilmetacrilato na face - Relato de caso. Arquivos Catarinenses de Medicina, 36 (1), 154-156.

França, K., Kumar, A., Fioranelli, M., Lotti, T., Tirant, M., \& Roccia, M. G. (2017). The history of Botulinum toxin: from poison to beauty. Wien Med Wochernschr, 167 (1), 46-48.

Hong, W. T., Kim, J., \& Kim, S. W. (2019). Minimizing tissue damage due to filler injection with systemic hyperbaric oxygen therapy. Archives of Craniofacial Surgery, 20 (4), 246-250.

Jacometti, V., Coltri, M. V., Santos, T. S., \& Silva, R. H. A. (2017). Procedimento de bichectomia: uma discussão sobre os aspectos éticos e legais em odontologia. Rev Bras Cir Plást, 32 (4), 616-623.

Kapoor, K. M., Kapoor, P., Heydenrich, I., \& Bertossi, D. (2019). Vision loss associated with hyaluronic acid fillers: A systematic review of literature. Aesthetic Plastic Surgery, 44 (1), 929-944.

Kim, Y. K., Jung, C., Woo, S. J., \& Park, K. H. (2015). Cerebral angiographic findings of cosmetic facial filler - related ophthalmic and retinal artery occlusion. J korean Med Sci, 30 (1), 1847-1855.

Klüppel, L., Marcos, R. B., Shimizu, I. A., Silva, M. A. D., \& Silva, R. D. (2018). Complications associated with the bichectomy surgery. RGO, 66 (3), 278284.

Lima, N. B., \& Soares, M. L. (2020). Utilização dos bioestimuladores de colágeno na harmonização orofacial. Clin Lab Res Den, 1-18. doi:10.11606/issn.2357-8041.clrd.2020.165832

Madeira, M. C. (2012). Anatomia da face: bases anatomofuncionais para a prática odontológica. (8a ed.), Sarvier.

Magri, I. O., \& Maio, M. (2016). Remodelamento do terço médio da face com preenchedores. Rev Bras Cir Plást, 31 (4), $573-577$.

Maia, I. E. F., \& Salvi, J. O. (2018). O uso do ácido hialurônico na harmonização facial: uma breve revisão. Bras J Surg Clin Res, 23 (2), $135-139$.

Manafi, A., Barikbin, B., Manafi, A., Hamedi, Z. S., \& Moghadam, S. A. (2015). Nasal alar necrosis following hyaluronic acid injection into nasolabial folds: A case report. World J Plást Surg, 4 (1), 74-78. 
Mannelli, G., Arcuri, F., Comini, L. V., Valente, D., \& Spinelli, G. (2019). Buccal fat pad: report of 24 cases and literature review of 1,635 cases of oral defect reconstruction. $O R L, 81(1), 24-35$.

Matos, M. B., Valle, L. S. E. M. B., Mota, A. R., \& Naves, R. C. (2017). O uso da toxina botulínica na correção do sorriso gengival - Revisão de Literatura. Braz J Periodontol, 27 (3), 29-36.

Nassif, P. W., Martos, S., \& Saturino, N. (2015). Relação de corpo estranho com infecção grave decorrente de preenchimento facial realizado por profissional não médico. Surg Cosmet Dermatol, 7 (4), 343-345.

Niamtu, J. (1999). Aesthetic uses of botulinum toxin A. J Oral Maxillofac Surg, 57 (1), 1228-1233.

Ortiz, A. E., Ahluwalia, J., Song, S. S., \& Avram, M. M. (2020). Analysis of U.S. Food and Drug Administration data on soft-tissue filler complications. Dermatologic Surgery, 46 (7), 958-961.

Papazian, M. F., Silva, L. M., Crepaldi, A., A., Crepaldi, M. L. S., \& Aguiar, A. P. (2018). Principais aspectos dos preenchedores faciais. Revista FAIPE, 8 (1), 101-116.

Parada, M. B., Cazerta, C., Afonso, J. P. J. M., \& Nascimento, D. I. S. (2016). Manejo de complicações de preenchedores dérmicos. Surg Cosmet Dermatol, 8 (4), 342-352.

Pereira, A. S., Shitsuka, D. M., Parreira, F. J., \& Shitsuka, R. (2018). Metodologia da pesquisa científica. RS: UFSM, NTE.

Prado, G., \& Rodríguez-Feliz, J. (2017). Ocular pain and impending blindness during facial cosmetic injections: is your office prepared? Aesth Plast Surg, 41 (1), 199-203.

Rayess, H. M., Svider, P. F., Hanba, C., Patel, V. S., DeJoseph, L. M., Carron, M., \& Zuliani, G. F. (2018). A cross-sectional analysis of adverse events and litigation for injectable fillers. JAMA Facial Plast Surg, 20 (3), 207-214. 10.1001/jamafacial.2017.1888

Ribas, M. O., Reis, L. F. G., França, B. H. S., \& Lima, A. A. S. (2005). Cirurgia ortognática: orientações legais aos ortodontistas e cirurgiões bucofaciais. $R$ Dental Press Ortodon Ortop Facial, 10 (6), 75-83.

Rodrigues L. G., Souza, J. B., Torres, E. M., \& Silva, R.F. (2017). Screening the use of informed consent forms prior to procedures involving operative dentistry: ethical aspects. JODDD, $11(1), 66-70$.

Sahan, A., \& Tamer, F. (2017). Non-surgical minimally invasive rhinoplasty: Tips and tricks from the perspective of a dermatologist. Acta Dermatovenerologica, 26 (1), 101-103.

Santamato, A., \& Panza, F. (2017). Benefits and Risks of non-approved injections regimens for botulinum toxins in spasticity. Drugs, 77 (13), $1413-1422$.

Shoughy, S. S. (2019). Visual loss following cosmetic facial filler injection. Arq Bras Oftalmol, 82 (6), 511-513.

Silva Neto, J. M. A., Silva, J. L. V., Mendonça, A. J. P. C., Duarte, I. K. F., \& Tenório Neto, J. F. (2019). O uso do ácido hialurônico na harmonização facial: Uma revisão de literatura. REAS, 32 (1), e1269.

Sito, G., Manzoni, V., \& Sommariva, R. (2019). Vascular complications after facial filler injection: A literature review and meta-analysis. J Clin Aesthet Dermatol, 12 (6), e65-e72.

Talarico, S., Hassun, K. M., Monteiro, E. O., Parada, M. O. B., Buratini, L. B., Arruda, L., \& Bagatin, E. (2010). Avaliação da segurança e eficácia de novo preenchedor à base de áido hialurônico no tratamento dos sulcos nasolabiais e contorno dos lábios. Surg Cosmet Dermatol, 2 (2), 83-86.

Tamura, B. M. (2013). Topografia facial das áreas de injeção de preenchedores e seus riscos. Surg Cosmet Dermatol, 5 (3), $234-238$.

Trindade De Almeida, A. R., \& Araújo Sampaio, G. A. (2015). Ácido hialurônico no rejuvenescimento do terço superior da face: revisão e atualização - Parte 1. Surg Cosmet Dermatol, 8 (2), 148-153.

Vargas, A. F., Amorim, N. G., \& Pintaguy, I. (2009). Complicações tardias dos preenchimento permanentes. Rev Bras Cir Plást, 24 (1), 71-81.

Vieira, G. M., Jorge, F. D., Franco, E. J., Dias, L. C., Guimarães, M. C. M., \& Oliveira, L. A. (2019). Lesions of the parotid gland and buccal artery after buccal fat pad reduction. J Craniofac Surg, 30 (3): 790-792.

Xu, J., \& Yu, Y. (2013). A modified surgical method of lower-face recontouring. J Aesth Plast Surg, 37 (1), $216-221$.

Zhang, H. M., Yan, Y. P., Qi, K. M., Wang, J. Q., \& Liu, Z. F. (2002). Estrutura anatômica da almofada de gordura bucal e suas adaptações clínicas. Cirur Plastic Reconst, 109 (7), 2509-2518. 